\title{
LÍNGUA PORTUGUESA E LIBRAS: DUAS LÍNGUAS QUE PRECISAM CONVIVER LADO A LADO
}

\author{
Aline Fernanda Alves Dias é professora de Língua Portuguesa e Literatura Brasileira no INES - Instituto Nacional de Educação de \\ Surdos-, doutoranda do Programa de Pós-graduação em Estudos da Linguagem da UFF e mestre em Linguística pela UERJ. \\ E-mail: line.nanda@ig.com.br
}

Resumo

O objetivo do artigo é abordar questões conflituosas que emergem no ensino de Língua Portuguesa para alunos surdos em escolas bilíngues. Algumas considerações da Linguística sobre o tema da afetividade serão apresentadas e discutidas ao longo do texto. A partir da discussão, buscamos sinalizar a importância de motivar os alunos surdos, identificando o papel da Língua Portuguesa.

\begin{abstract}
This paper discusses some problematic issues concerning Portuguese language teaching to deaf students in bilingual schools. Some linguistics considerations on affectivity will be presented and discussed throughout the paper. From the discussion, we signaled the importance of motivating students deaf, identifying the role of the Portuguese language.
\end{abstract}

\section{Introdução}

Na literatura que se dedica ao estudo da Língua Brasileira de Sinais (LIBRAS), é possível observar congruência em relação à abordagem de seu status como língua natural da comunidade surda (cf., dentre outros, Felipe, 1989; Ferreira Brito, 1995; Quadros, 1997, 1999, 2000; Quadros \& Karnopp, 2004). Tal fato confere a importância necessária a LIBRAS, que, desde 24 de abril de 2002, com a lei $\mathrm{n}^{\circ} 10.436$ (Brasil, 2002), é reconhecida oficialmente como o idioma da comunidade surda brasileira.

Por outro lado, a referida lei destaca que, na modalidade escrita, a LIBRAS não poderá substituir a Língua Portuguesa. Por essa razão, o ensino da Língua Portuguesa, idioma oficial do Brasil, deve ser garantido aos surdos na modalidade escrita. Desse modo, no momento, o que vem sendo proposto para a educação de surdos é que se tenha um ensino bilíngue (cf. Quadros, 1997), em que a língua de instrução seja a LIBRAS, sua língua natural, e a língua escrita, a Língua Portuguesa.

Embora se reconheça a importância de ambas as línguas para o cidadão surdo, naturalmente é travado um confronto entre aquela que é, reconhecidamente e espontaneamente, própria de sua comunidade e aquela que, a princípio, pertence ao cidadão ouvinte. Soma-se a esse quadro também o fato de que ensinar a modalidade escrita de uma língua oral, por um professor ouvinte, a uma pessoa surda não é tarefa fácil, resultando em constantes desapontamentos entre professores ouvintes e alunos surdos, o que agrava ainda mais as circunstâncias.

Nessa perspectiva, o presente artigo pretende, a partir das considerações que têm sido realizadas pela Linguística, em especial pela Linguística Aplicada (Krashen, 1988; Revuz, 1998; Venturi, 2006), sobre o ensino de segunda língua, discorrer sobre questões 
que permeiam o ensino de Língua Portuguesa escrita a alunos surdos, no sentido de abordar aspectos que parecem atravancar esse processo e aspectos que possam ajudá-lo. Dessa maneira, pretendemos manifestar, a partir de nossa vivência em sala de aula com alunos surdos, nossos anseios e também nossas considerações para aquilo a que nos dedicamos: o ensino da Língua Portuguesa.

\section{1) LIBRAS: a língua da comunidade surda brasileira}

Sendo a língua um módulo da cognição, todo ser humano possui disposição para desenvolvê-la durante o percurso de sua vida, desde que apresente condições neurológicas normais e esteja inserido em condições ambientais satisfatórias para o desenvolvimento linguístico. Desse modo, ainda que privada de audição, a criança mantém a habilidade para a aquisição da linguagem. Entretanto, as pistas linguísticas oriundas de línguas auditivo-orais não lhes são alcançáveis com a naturalidade esperada para esse processo, mas sim aquelas oriundas do espaço visual, dessa forma:

As diferentes linguagens de sinais seriam, pois, línguas naturais e simples variantes de línguas articuladas. Segue-se que a aquisição do sistema linguístico assenta em estruturas genéticas extremamente abstractas e não sobre a nossa capacidade auditiva e fônica. Enquanto o bebê pode adquirir a linguagem de sinais se for exposto a este sistema durante os seus primeiros anos, mais tarde a aprendizagem não é nem tão fácil nem tão completa. O que acontece, portanto, é que um sistema específico, que se apoia em certas estruturas do córtex, manifesta-se desde que o bebê seja posto em presença de um meio favorável e possa ser estimulado para favorecer o desenvolvimento quer da linguagem verbal quer da linguagem gestual. (Mehler e Dupoux, 1994, pag.186)

Muitos autores que se dedicam aos estudos linguísticos sobre a surdez destacam ser a LIBRAS a manifestação de uma língua natural, visto que a ausência de audição propicia o desenvolvimento espontâneo de uma língua gestual (cf., dentre outros, Stokoe, 1960; Quadros, \& Karnopp, 2004). Dessa maneira, o que difere a aquisição de uma língua de sinais da aquisição de uma língua oral é o tipo de input necessário para que se desencadeie o processo, para esta são dados orais e para aquela, visuais.

Nesse sentido, no período crítico de aquisição da linguagem (Lenneberg, 1967), a primeira língua (L1) que emerge espontaneamente entre os surdos é a língua de sinais, desde que haja o contato com o input adequado. A Língua Portuguesa representará para o surdo uma segunda língua (L2), entretanto, adquirida por meio de uma prática sistemática, ou seja, que necessita de estratégias específicas e de um ensino formal. Difere-se, dessa forma, da aquisição de uma L2 em um contexto de bilinguismo simultâneo, como os casos de filhos de pais que possuem línguas diferentes e que, por isso, adquirem as duas línguas simultaneamente, e de bilinguismo espontâneo, como os casos, por exemplo, de pessoas que passam a viver em um país em que se fala uma língua diferente da sua (cf. Quadros, 1997). 
Assim, segundo Quadros (1997), a criança surda passa por estágios de aquisição da linguagem semelhantes àqueles por que passa uma criança ouvinte: pré-linguístico, estágio de um sinal, estágio das primeiras combinações e estágio das múltiplas combinações.

Para reafirmar o que foi acima exposto, nas últimas abordagens da Teoria Linguística, (Chomsky, 1995, 1998, 2005, 2007, dentre outros), a Faculdade da Linguagem (FL) tem sido tratada numa perspectiva de articulação com os chamados sistemas de desempenho. A FL seria um módulo da cognição articulado aos sistemas articulatório-perceptual e conceitual-intencional, que seriam responsáveis por conferir forma e significado às expressões linguísticas. Assim, essas expressões, que são geradas a partir de um léxico e de um sistema computacional, o qual é responsável pela formulação sintática, são acessadas pelos sistemas cognitivos de performance, responsáveis pela interface com a FL, representados pelos subsistemas Forma Fonética (PF) e Forma Lógica (LF), conforme reprodução da ilustração de Kenedy e Abraçado (2011, pag. 23):

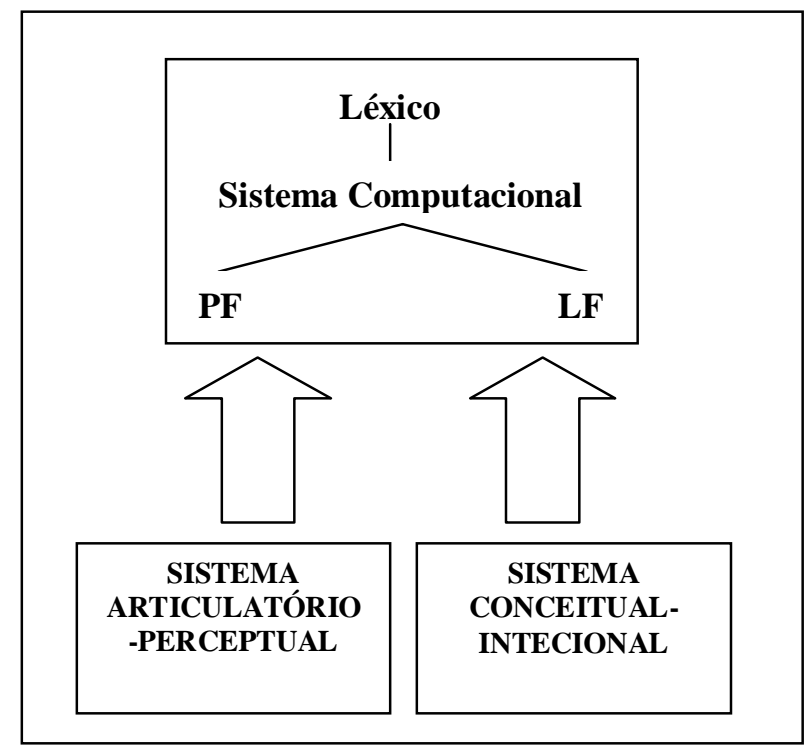

Fig.1: Arquitetura da Faculdade da Linguagem no Programa Minimalista (Kenedy e Abraçado, 2011)

Desse modo, tal sistema articulatório-perceptual não está vinculado à audição apenas, mas pode, claramente, corresponder às habilidades visual e gestual. A arquitetura da FL - léxico e um sistema computacional - é, portanto, a mesma para o surdo. Segundo Quadros (1998), a observação de que o termo articulatório não se limita às línguas faladas, mas expressa a forma pela qual a linguagem será representada na interface articulatório-perceptual, inclui as línguas de sinais, reconhecendo-as, portanto, no universo das investigações linguísticas. 
Nesse âmbito, as propriedades da LIBRAS têm sido, há algum tempo, alvo das investigações linguísticas (cf. dentre outros, Felipe, 1989; Ferreira Brito, 1995; Quadros, 1997, 1999, 2000; Quadros \& Karnopp, 2004). Os autores buscam determinar suas características nos diferentes níveis linguísticos - sintaxe, fonologia, morfologia, semântica e pragmática-, colaborando, assim, para sua descrição e seu entendimento. Esses estudos, ao listarem as peculiaridades linguísticas da língua, lançam luz sobre a consideração de que a LIBRAS é um sistema linguístico legítimo, portanto, uma língua natural.

Dessa forma, há razões bastante contundentes para assumir que a língua da comunidade surda brasileira é a LIBRAS, uma vez que se desenvolveu e se desenvolve espontaneamente entre os indivíduos surdos no Brasil, funcionando como meio de comunicação e expressão do pensamento, emoção, sentimentos, dentre outros, tal como procede entre os falantes nativos Língua Portuguesa. Por essa razão, o justo movimento em defesa da garantia ao direito de acesso à LIBRAS em condições iguais às que crianças ouvintes brasileiras têm à Língua Portuguesa é importante na medida em que promove a conscientização não só daqueles diretamente envolvidos com o processo familiares, profissionais e professores de surdos -, mas também da população como um todo, a qual deve reconhecer a legitimidade desta minoria linguística.

Nesse contexto, as primeiras políticas linguísticas que levam em consideração a língua e a comunidade surda no Brasil surgem a partir de uma luta travada para que se reconhecesse o direito linguístico e social da LIBRAS:

Os movimentos sociais alavancados pelos surdos estabeleceram como uma de suas prioridades o reconhecimento da língua de sinais nos últimos 15 anos. Foram várias as estratégias adotadas para tornar pública a Língua Brasileira de Sinais (LIBRAS). Entre elas, citamos os projetos-lei encaminhados em diferentes instâncias governamentais e a formação de instrutores de língua de sinais em vários estados brasileiros. Instaurouse em várias unidades da Federação a discussão sobre a "língua de sinais dos surdos", determinando o reconhecimento, por meio da legislação, dessa língua como meio de comunicação legítimo dos surdos. Esse movimento foi bastante eficiente, pois gerou uma série de iniciativas para disseminar e transformar em lei a língua de sinais brasileira, culminando na lei federal 10.436, 24/04/2002, que a reconhece no país. (Quadros, 2007, pag. 142)

Embora tenha sido reconhecida oficialmente em 2002 e, desde 2005, por meio do Decreto $\mathrm{n}^{\mathrm{o}} 5626$ (Brasil, 2005), haja uma determinação de que se formem profissionais que trabalhem nessa área, essa luta vem de muito antes dessa data, como pudemos observar nas considerações de Quadros (2007). Mesmo hoje, sabe-se que ainda há muitos caminhos a serem trilhados para que se respeitem tais direitos e se consolidem práticas que garantam ao surdo uma educação bilíngue satisfatória. Para isso, muitas pesquisas têm buscado mostrar desde a significância do incentivo à língua e cultura surda à busca por materiais adequados a uma realidade diferente da realidade ouvinte (cf., dentre outros, Silva et al, 2011). Assim, essa mobilização propicia, de 
forma natural, a formação de um cenário que dá voz ao que, até então, havia sido silenciado.

\section{2 ) O reconhecimento de uma língua e seus desdobramentos}

O prestígio sociolinguístico da Língua Portuguesa padrão frente às minorias linguísticas - não apenas à LIBRAS, mas também às demais línguas existentes no território nacional, como as línguas indígenas, por exemplo - representa a complexidade das questões que envolvem poder e língua na sociedade brasileira (cf. Bagno, 2003). Devido a esse complexo de fatores, são necessárias políticas linguísticas que garantam a legitimidade das demais línguas que compõem o panorama linguístico nacional (cf. Cavalcanti, 1999). Consequentemente, a LIBRAS se insere no grupo das minorias linguísticas que coexistem no Brasil e, como tal, também requer um movimento que a reconheça e legitime. Nesse contexto, há estudos que buscam sinalizar a representatividade da LIBRAS para o surdo e, assim, garantir seu lugar na sociedade em diferentes espaços (cf., dentre outros, Quadros, 2007).

O modelo educacional imposto à comunidade surda foi, durante muitos anos, pautado na língua falada (Quadros, 2007). Esse modelo que visa apenas à oralização não garante, contudo, o espaço necessário à língua espontânea da comunidade surda, sua artificialidade requer muito esforço do aluno e não lhe garante sucesso no aprendizado.

Outra proposta corresponde ao português sinalizado, que enfatiza o bimodal. $\mathrm{O}$ propósito desta é o desenvolvimento da língua oral, permitindo, entretanto o uso da LIBRAS, simultaneamente à língua falada. A esse modelo coube também muitas críticas, já que o uso de duas línguas ao mesmo tempo propicia a descaracterização de ambas, não permitindo que o educando surdo desenvolva naturalmente sua língua e oferecendo um ensino incompleto da língua oral (Quadros, 1997).

Aos poucos, as pesquisas demonstraram que os modelos acima mencionados não contemplavam a educação de surdos nem respeitavam suas diversidades. Dessa maneira, reivindicou-se uma educação que reconhecesse a LIBRAS e a cultura surda. Assim, o bilinguismo foi apontado como o melhor modelo para a educação desses alunos:

O bilinguismo é uma proposta de ensino usada por escolas que se propõem a tornar acessível à criança surda duas línguas no contexto escolar. Os estudos têm apontado para essa proposta como sendo mais adequada para o ensino de crianças surdas, tendo em vista que considera a língua de sinais como língua natural e parte desse pressuposto para o ensino da língua escrita. (Quadros, 1997, pag. 27)

Nessa proposta, acredita-se dar o devido reconhecimento à língua e cultura surdas, uma vez que se reconhece a LIBRAS como a língua espontânea da referida comunidade e a língua escrita como um mecanismo artificial, que deverá ser aprendido 
pelo aluno por meio de uma metodologia de ensino de segunda língua. O bilinguismo permite ainda que se crie um ambiente escolar que dê lugar às manifestações da comunidade surda, uma vez que, sendo a língua um fenômeno complexo, que envolve desde aspectos biológicos a aspectos socioculturais, com a sua construção emergem, naturalmente, questões de identidade. "A língua de sinais para os surdos é a possibilidade de adentrar e significar o mundo" (Quadros, 2007, pag.08).

Como durante muitos anos, os surdos não tiveram seu espaço reconhecido, já que a eles a língua oral foi imposta a todo custo, sem haver o devido reconhecimento da língua gestual, todo o esforço e movimento feito para a reversão desse quadro provoca um sentimento de afirmação, silenciado durante anos de proibição da língua de sinais em sala de aula (cf. Quadros, 2007). É, portanto, intrínseco a esse momento um sentimento de reivindicação dos direitos linguísticos e socioculturais.

Posta a legitimidade da língua, os espaços vão sendo conquistados à medida que a própria comunidade surda se organiza politicamente para assegurá-los:

Os próprios surdos tomam a frente dos movimentos para reconhecimento legal. Os surdos reivindicam a presença de intérpretes de língua de sinais em diferentes espaços, incluindo os espaços de negociação com os ouvintes para pensarem e definirem aspectos relacionados com a vida dos surdos. Dessa forma, a autoria surda passa a ser representada em algumas instâncias delineando o período pós-colonialista em relação aos surdos brasileiros. Isso se traduz na presença dos surdos no Ministério da Educação, na restrição do ensino da língua de sinais aos instrutores necessariamente surdos, na articulação dos movimentos surdos, na legislação. (Quadros, 2007, pag. 6-7)

A busca por material didático adequado a essa realidade é mais um exemplo de reivindicação que é amplamente discutida na literatura sobre a área. Em relação à disciplina de Língua Portuguesa, por exemplo, como a perspectiva é de um ensino de segunda língua, não há como esperar que o material direcionado ao aluno ouvinte, que possui a Língua Portuguesa como língua materna, seja empregado satisfatoriamente na educação de surdos. Portanto, a organização de material adequado é uma grande preocupação daqueles que estão envolvidos com a causa.

A construção desse material numa educação bilíngue para surdos exige, entretanto, um imenso esforço no sentido de adaptar a metodologia de ensino de língua estrangeira ao contexto da surdez. Não há como ignorar a vivência visual do surdo, por isso, as pesquisas sinalizam a necessidade de que se empreguem estratégias adequadas no processo de ensino-aprendizagem, não deixando de lado as questões que envolvem a constituição dessa língua. Segundo Silva et al.(2011), "com base nisso, acreditamos que ao produzir materiais didáticos para surdos seja necessário uma maior sensibilidade para as questões linguísticas, culturais e de identidade que envolvem o contexto da surdez".

Nesse mesmo processo de conquista de seus espaços, entende-se que a formação do profissional que atuará em sala de aula seja um outro ponto importante. Propõe-se que o profissional ouvinte que venha a ministrar as aulas em LIBRAS deva não só ter fluência nessa língua, como também considerar todas as particularidades que envolvem 
o universo da surdez. Nesse sentido, todas as questões apontadas em relação às diversidades linguísticas e culturais devem ser consideradas pelo professor ouvinte, reconhecendo a representatividade da LIBRAS, sua importância para o reconhecimento do sujeito surdo e para a aquisição do conhecimento.

Segundo Quadros (1997), é justamente por haver a necessidade que se considere não apenas a diversidade linguística, mas também a diversidade cultural, que seria justo que a escola abraçasse não apenas uma educação bilíngue, mas uma educação bicultural:

Deve-se atentar, também, para as culturas nas quais a criança está inserida. A comunidade surda apresenta uma cultura própria que deve ser respeitada e cultivada. Ao mesmo tempo, a comunidade ouvinte tem sua cultura. Por isso, uma proposta puramente bilíngue não é viável. Uma proposta educacional além de ser bilíngue, deve ser bicultural para permitir o acesso rápido e natural da criança surda à comunidade ouvinte e para fazer com que ela se reconheça como parte de uma comunidade surda. Isso somente será possível quando os educadores e surdos trabalharem juntos. (Quadros, 1997, pag.28)

Assim, a gradativa conquista de espaço na sociedade brasileira implica um processo de reivindicação justa dos direitos da comunidade surda. Como foi pontuado, esse movimento não é recente. Muitos surdos se referem aos anos de escolarização pautada na língua oral como um período de sofrimento, em que a manifestação natural e espontânea da língua gestual era proibida. Desse modo, o cenário desenhado é o de uma comunidade que foi bastante oprimida e que agora vem batalhando para que seja respeitada.

No entanto, para alguns autores as políticas linguísticas ainda não atendem satisfatoriamente a demanda dos surdos brasileiros (cf., dentre outros, Quadros, 2007; Silva et al., 2011). No discurso empregado, demonstra-se haver ainda uma longa trajetória a ser percorrida até que se tenha, de fato, a garantia de igualdade:

Já se reconhece que a língua de sinais é a primeira língua, que a língua portuguesa é uma segunda língua, já se sabe da riqueza cultural que o povo surdo traz com suas experiências sociais, culturais e científicas. Neste momento pós-colonialista, a situação bilíngue dos surdos está posta, no entanto, os espaços de negociação ainda precisam ser instaurados. As políticas linguísticas ainda mantêm uma hierarquia vertical entre o português e as demais línguas no Brasil, apesar de algumas iniciativas no sentido de reconhecimento das "diversidades" linguísticas do país. (Quadros, 2007, pag. 8)

Dessa maneira, a Língua Portuguesa, idioma oficial do Brasil, acaba representando para o surdo a soberania que ainda oprime as demais variedades linguísticas coexistentes no território nacional. De certo modo, trava-se um confronto entre o educando surdo e a Língua Portuguesa, corporificada na figura do professor ouvinte, que a detém como língua materna. Acreditamos que isso seja um processo natural de confronto entre a língua oprimida e a língua prestigiada. Entretanto, também 
cremos que todo esforço deve ser feito no sentido de garantir a esse aluno sua plena inclusão na sociedade.

Para isso, é necessário que haja desde uma boa formação de um profissional para atuar nesse contexto à conscientização do aluno surdo para a importância da Língua Portuguesa escrita para a sociedade em que vivem surdos e ouvintes, os quais partilham, de algum modo, das mesmas experiências socioculturais e mesmo linguísticas. Não podemos negar o fato de que é importante para qualquer cidadão brasileiro o domínio da leitura e escrita do idioma oficial. A plena consciência de que essa não é uma questão simples suscita em nós reflexões acerca do tema que buscaremos abordar a seguir.

\section{3) Aula de Língua Portuguesa: um espaço de confronto ou de construção do conhecimento?}

Sendo a Língua Portuguesa uma L2 para o surdo, uma vez que sua L1 seja a LIBRAS, utilizaremos os termos aprendizado e aquisição para fazer referência ao processo que desencadeia as duas, utilizando a diferenciação proposta por Krashen (1988). Acreditamos que este seja um primeiro ponto a ser aludido, a fim de que possamos tratar das questões que permeiam o ensino de Língua Portuguesa para surdos.

$\mathrm{Na}$ abordagem de Krashen, a aquisição corresponderia a um processo intuitivo, que acontece no subconsciente e ocorre por necessidade de comunicação, naturalmente. Por outro lado, a aprendizagem é concebida como um processo consciente, em que o aprendiz reconhece formalmente as regras gramaticais, portanto, uma ação consciente. Desse modo, concebemos que o aprendiz surdo passa por um processo de aprendizagem da Língua Portuguesa, pois aquisição, inconsciente e espontânea, concerne à LIBRAS, justificando, assim, o diferente grau de dificuldade entre as duas.

Posta essa diferenciação, ainda em relação às propostas de Krashen, o autor sugeriu, no Modelo do Monitor (1978), que haja uma espécie de monitor na aquisição de uma L2, que seria o resultado de uma aprendizagem e que atuaria como uma fiscalização feita a partir do conhecimento consciente de regras gramaticais. Dessa maneira, o uso da L2 seria conduzido por uma consciência dessas regras, quando na L1 o uso é conduzido com naturalidade, sem a atuação de um monitor. Desse modo, o aprendizado da Língua Portuguesa escrita pelo surdo dependeria também dessa consciência de regras gramaticais, o que torna o processo mais complexo, exigindo grau de esforço muito maior do educando.

Um outro princípio desse modelo que consideramos muito relevante para nossas reflexões - na verdade, consideramos o centro das questões que, por ora, pretendemos levantar - é a hipótese do filtro afetivo. Tal hipótese reside na crença de que, no aprendizado de uma L2, haja fatores de motivação intrínsecos ao contexto. Diferentemente do que acontece com a aquisição da língua materna, que ocorre espontaneamente, naturalmente, sem necessidade de que sejam postos fatores motivacionais, o aprendizado de uma L2 implica circunstâncias que o favoreçam, no 
sentido de haver aspectos que estimulem o desejo de se aprender a outra língua. A motivação e a autoconfiança desempenham, portanto, papel fundamental para que se aprenda de maneira bem sucedida uma L2.

Por envolver aspectos muito diferentes, pelo fato da possibilidade de insucesso, pelos fatores que estão em jogo durante o processo, dentre outros, concebe-se ser o aprendizado de uma segunda língua procedimento muito diferente da aquisição da língua materna. Por isso, muitas pesquisas linguísticas buscam contribuir de alguma forma para o ensino de L2, apontando desde estratégias a serem empregadas a fatores que possam representar obstáculos. Nesse sentido, a hipótese do filtro afetivo lança luz sobre a importância da afetividade no aprendizado de uma L2.

A Linguística Aplicada (LA) tem-se destacado em relação à abordagem de problemas em sala de aula de língua materna e língua estrangeira. Ramo da Linguística que se preocupa com problemas reais de uso da linguagem e da comunicação, a LA busca em diferentes áreas contribuições para solucioná-los (Menezes et al., 2009). As Ciências Cognitivas, a História Social, a Sociologia, a Psicolinguística e a Psicologia são algumas delas. A questão da afetividade está, portanto, no rol das preocupações dos pesquisadores dessa área, os quais aliam os estudos linguísticos a outras disciplinas, a fim de resolver problemas de uso da linguagem.

Como exposto, há muitos problemas a serem discutidos quando o assunto é o aprendizado de uma segunda língua. A maneira como se conduz o aprendizado por parte do professor, o nível de conscientização dos mecanismos linguísticos por parte do aluno e os fatores afetivos são apenas alguns deles. Entretanto, dispensaremos, neste momento, maior atenção aos fatores afetivos, pois acreditamos que, em relação ao ensino de Língua Portuguesa escrita a aprendizes surdos, esses podem representar um desafio a ser superado.

Mencionamos anteriormente que foram muitos anos de luta para que a LIBRAS fosse, justamente, reconhecida como língua da comunidade surda. Tal fato causou um impacto natural na comunidade, um movimento de afirmação de seus direitos linguísticos e socioculturais, reivindicando-se condições de acesso a esses direitos. Assim, passa a haver um incentivo maior à formação de intérpretes, uma defesa de escolas bilíngues para surdos, busca por materiais adaptados para LIBRAS, etc.

Entretanto, a Língua Portuguesa continua ocupando um espaço significativo no universo da pessoa surda, uma vez que o sistema de escrita ensinado e utilizado é baseado nessa língua. Desse modo, existem duas línguas atuando no contexto da escola bilíngue, a LIBRAS, como língua de instrução, e a Língua Portuguesa, como modalidade escrita, representando a L2.

Uma modalidade escrita é para qualquer pessoa um mecanismo artificial, composto por convenções que simbolizam a língua natural. Para o ouvinte falante de Língua Portuguesa, entretanto, a modalidade escrita representa a mesma estrutura de sua língua oral, fazendo, portanto, bastante sentido para ele. Ainda assim, é válido lembrar que o ensino de uma língua materna, mesmo para a comunidade ouvinte, é um processo 
longo e que requer uma metodologia adequada para que se alcance o grau de letramento desejado para leitura e escrita. Há, dessa forma, muitas pesquisas linguísticas que se dedicam a esse tema (cf. dentre outros, Bagno, 2002).

Por outro lado, o apoio que o ouvinte encontra em sua língua materna está ausente para o surdo. Se o ouvinte pode, por exemplo, se apoiar no som que conhece das palavras, o surdo não pode fazê-lo. Assim, o sentido que a escrita da Língua Portuguesa tem para falantes nativos não é o mesmo, obviamente, para o surdo, tornando o processo de ensino-aprendizagem desta bastante singular e difícil nesse contexto específico.

Dessa maneira, acreditamos que seja particularmente complexo, em parte, porque o surdo aprende a escrever pela primeira vez em uma segunda língua. Basta que nós, ouvintes, imaginemos como seria aprender a ler e escrever em uma língua estrangeira sem que nunca tivéssemos aprendido a ler e escrever em nossa língua materna. Existem já pesquisas que demonstram essa preocupação com a escrita da LIBRAS (cf. dentre outros, Quadros, 1998; Lessa de Oliveira, 2012). Segundo Quadros (1998), com a alfabetização em LIBRAS, todos os níveis desse processo apareceriam em crianças surdas, que seriam alfabetizadas por meio de interação com a escrita da língua de sinais, com grafemas, sílabas e palavras que representariam a LIBRAS. Acreditamos que, se ocorresse tal processo com os surdos, o aprendizado de uma L2, na modalidade escrita, seria, de fato, facilitado. Por outro lado, acreditamos que tal complexidade seja ainda maior devido a fatores que ultrapassam questões estritamente linguísticas, questões que dizem respeito à representação subjetiva que a Língua Portuguesa assume para o surdo.

Existem muitos fatores, como apontamos, para que a aprendizagem da escrita da Língua Portuguesa por alunos surdos represente uma tarefa árdua e difícil. Entretanto, a escrita representa o acesso às informações que compõem a sociedade em que vivem, deve ser considerada, por isso, importante mecanismo de integração dos surdos. Tal como o ouvinte, eles interagem utilizando bastante esta modalidade, uma vez que usam sites de relacionamento, trocam mensagens nos celulares, leem jornais, escrevem cartas, bilhetes, enfim, usam todas as ferramentas visuais disponíveis para a comunicação e informação como qualquer ouvinte.

Se por um lado parece haver entre os surdos um consenso de que a escrita da Língua Portuguesa é meio para interação, tanto com surdos quanto com ouvintes, e meio de acesso às informações em espaços onde somente uma modalidade escrita pode cumprir esses papeis, por outro, isso pode representar também uma disputa de espaço e poder. Diante de todo o movimento de conquista, a que nos remetemos anteriormente, continuar assumindo a importância indispensável da Língua Portuguesa pode significar um confronto entre a relevância desta e a da LIBRAS no universo da surdez. Esse cenário é ainda agravado diante das constantes frustrações e fracassos gerados por uma aprendizagem mal sucedida da língua escrita, potencializando no surdo a iniciativa de defesa de sua língua materna como sendo a única capaz de lhe representar. 
É importante sinalizar que essas são considerações feitas com base em nossa vivência em sala de aula de colégio bilíngue para surdos. Desse modo, percebemos que, por diversas vezes, em diversos contextos, esse conflito é travado entre as duas línguas. Alguns exemplos são os casos em que o aluno se recusa a escrever, justificando que não consegue porque Português é muito difícil e os casos em que os alunos julgam a LIBRAS do professor ouvinte precária. Acreditamos serem esses sinais vitais de uma relação que se configura conflituosa e que precisa, portanto, de muita atenção.

Se o aluno se recusa a escrever pode ser, muito provavelmente, por falta de sensibilidade de todos aqueles que compartilham de suas experiências - pais, familiares, professores, demais profissionais e outros - em compreender a dificuldade dessa tarefa, pontuando todos os erros e defeitos de seu texto, preocupando-se menos com a sua iniciativa e mensagem, consequentemente, desestimulando-o. A ausência de mecanismos gramaticais pode parecer, para alguns ouvintes, invalidar completamente um texto que pode sim fazer sentido quando analisado sem se ater a todas as normas.

Gostaríamos de esclarecer, no entanto, que não significa atribuir pouca importância à aprendizagem das regras gramaticais que subjazem à Língua Portuguesa padrão, porém estamos preocupados em salientar que, por diversas vezes, o texto de um aluno surdo cumpre, coerentemente, a transmissão de uma mensagem, faltando-lhe apenas mecanismos como preposição, tempo verbal e concordância, por exemplo. Dessa maneira, o mais importante para a comunicação, a concatenação de ideias, procede, precisando, no entanto, que seja dispensado mais tempo para a aquisição das formalidades gramaticais.

No que se refere ao outro exemplo, quando o aluno desaprova a LIBRAS do professor, parece haver, no fundo, uma demonstração de que ele também detém o poder de dominância de uma língua, tal como fazem os ouvintes ao pontuarem seus erros textuais. Assim, muitas vezes o professor também se sente desestimulado e frustrado e, consequentemente, a sala de aula passa de em espaço de construção do conhecimento a um espaço de confronto:

A língua estrangeira, objeto de saber, objeto de uma aprendizagem raciocinada é, ao mesmo tempo, próxima e radicalmente heterogênea em relação à primeira língua. $\mathrm{O}$ encontro com a língua estrangeira faz vir à consciência alguma coisa do laço muito específico que mantemos com nossa língua. Esse confronto entre primeira e segunda língua nunca é anódino para o sujeito e para a diversidade de estratégias de aprendizagem (ou de não aprendizagem) de uma segunda língua, que se pode observar quando se ensina uma língua e se explica, sem dúvida, em grande parte pelas modalidades desse confronto. (Revuz, 1998, pag. 215, grifo do autor)

Esse confronto é bastante perturbador, pois pode proporcionar a criação de um abismo entre professor e aluno. Uma vez instaurada essa configuração de sala de aula, buscar estratégias para o ensino de questões puramente linguísticas, formais, parece insuficiente, pois existe uma barreira a ser rompida antes de qualquer outra coisa, a da afetividade. 
Segundo Venturi (2006), fatores como relações de poder, emoção, afeto, expectativas culturais, identidade e autoestima são fundamentais no processo de aprendizagem de uma L2. Assim, acreditamos que esses aspectos são essenciais e não podem ser esquecidos no ensino de Língua Portuguesa a alunos surdos. É importante que o professor tenha consciência desses fatores, a fim de estimular a aprendizagem da segunda língua. Deve haver uma preocupação com os aspectos emocionais, a fim de criar condições para tratar dos demais aspectos. Acreditamos que, somente incentivando o aluno surdo, haverá condições de que ele se sinta motivado a aprender a segunda língua. Na verdade, é necessário que ele sinta que essa língua também o representa, que ela também é sua língua.

Não podemos ignorar a importância da Língua Portuguesa escrita para o surdo, assim como para qualquer cidadão brasileiro. Acreditamos que, para isso, é preciso começar a romper barreiras que separam surdos e ouvintes, é preciso mostrar que compartilhamos experiências por meio da mesma língua, esta que lemos em toda parte do Brasil, que está nos sites de relacionamento, na TV, nos jornais, nas revistas, nos manuais, nos livros, nos documentos...

Reiteramos que isso não significa, em hipótese alguma, questionar a importância do status da LIBRAS para a comunidade surda. Pelo contrário, acreditamos que somente assegurando a aquisição da L1 é possível o aprendizado satisfatório da L2. Acreditamos ainda que o reconhecimento da LIBRAS também é parte fundamental dos aspectos afetivos que devem conduzir o aprendizado e que, por essa razão, devemos "respeitar a língua do outro, depositária insubstituível das identidades individuais e coletivas (Revuz, 1998, pag.229).

No entanto, partimos de uma lógica perigosa se não garantimos espaço à Língua Portuguesa na comunidade surda. Ignorarmos a sua importância significa não dar espaço à realidade e, paradoxalmente, não oferecer condições absolutas de inclusão ao surdo. Sabemos que, por diversos motivos, dentre os quais a inserção no mercado de trabalho, é cada vez mais importante o domínio da leitura e escrita. Faz, portanto, muito sentido mostrarmos aos nossos alunos que existe um esforço a ser feito, mas que visa à conquista de seu espaço na sociedade, sociedade composta por ouvintes e surdos, cidadãos brasileiros. Não significa deixar de lutar para que a LIBRAS continue ocupando espaço nessa mesma sociedade, continuar incentivando ouvintes a também adquiri-la é justo.

Para que isso seja possível, entretanto, a questão do filtro afetivo merece atenção especial e, nesse sentido, a motivação é uma importante peça. Portanto, além do que já destacamos - não pontuar apenas seus erros e reconhecer a importância de sua língua materna, por exemplo -, é preciso criar estratégias também voltadas para essa questão. A nosso ver, os adultos surdos podem contribuir significativamente para isso, a partir de seus relatos de experiências, mostrando ao aluno jovem a importância que a Língua Portuguesa exerce em âmbitos variados, mostrando-lhe ainda que o aprendizado desta 
permite autonomia para a aquisição do conhecimento, uma vez que permite a leitura e, consequentemente, o acesso à informação.

Não raro, observarmos haver entre os surdos adultos grau de conscientização muito maior em relação a esse aspecto e, por isso, sua atuação é indispensável. Eles reconhecem a importância das conquistas da comunidade surda, reconhecem ser a LIBRAS a língua natural de sua comunidade e reconhecem que há muito o que ser feito para continuar garantindo os seus direitos. Entretanto, eles também reconhecem a importância da leitura e escrita, reconhecem que sem elas não há inclusão verdadeira, reconhecem que é por meio dela também que se conquista espaço:

\begin{abstract}
Agora sei que a minha língua é a língua de sinais. Agora sei também que o português me convém. Eu quero ensinar português para os meus alunos surdos, pois eles precisam desta língua para ter mais poder de negociação com os ouvintes. (G.2004 apud Quadros, 2007, pag.8)
\end{abstract}

Sabemos que a motivação na aprendizagem de L2 pode ser de diferentes naturezas. Pode ser por questões pessoais, por questões mais práticas, por questões de identificação com a comunidade linguística. Dessa maneira, muitas podem ser as razões que levam o aprendiz a se sentir motivado a aprender uma segunda língua. Seja de qual for a natureza, essa variável cumpre um papel facilitador nessa empreitada. Destacamos, assim, a impossibilidade de ignorá-la, sob pena de fracassarmos no aprendizado de Língua Portuguesa como L2 para a comunidade surda.

Todavia, esse deve ser um empenho coletivo, empenho de todos aqueles que atuam, de alguma forma, nesse processo. Os professores de Língua Portuguesa necessitam de uma ação conjunta, em que todos estejam sintonizados no mesmo objetivo, ensinar o educando surdo a ler e a escrever, e mais, ensiná-lo a gostar da Língua Portuguesa.

\title{
Considerações Finais
}

No presente artigo, buscamos abordar questões sobre o processo de ensinoaprendizagem da Língua Portuguesa a partir de nossa experiência em sala de aula numa escola que apresenta proposta bilíngue para o ensino de alunos surdos. Nesse sentido, procuramos dar voz a anseios que, de alguma forma, parecem representar não apenas os nossos, mas também de outros profissionais que atuam nesse contexto.

Nossa preocupação, primeiramente, foi demonstrar de que maneira os estudos linguísticos vêm atuando na afirmação da LIBRAS como uma língua natural, que emerge espontaneamente entre os surdos. Em seguida, abordamos os reflexos provenientes do reconhecimento oficial dessa língua na sociedade brasileira após anos de luta, demonstrando os movimentos de afirmação e de esforço para que sejam garantidos os seus direitos. 
Não obstante o reconhecimento da LIBRAS, a Língua Portuguesa na modalidade escrita, continua fazendo parte da vida do surdo, cidadão brasileiro. Tal fato acrescido dos insucessos oriundos de uma aprendizagem mal estruturada parece propiciar um cenário de confronto entre as duas línguas. Como a sala de aula é o local em que elas se encontram constantemente, o espaço que deveria ser majoritariamente de construção do conhecimento cede lugar a conflitos entre o professor e o aluno.

Desse modo, consideramos importante o fator já apontado pelas pesquisas linguísticas em ensino de segunda língua, no caso, a afetividade. Assim, por razões citadas nos capítulos anteriores, consideramos ser a motivação peça essencial de nosso trabalho, na medida em que cumpriria papel facilitador no processo de ensinoaprendizagem.

Antes de estratégias bem estruturadas para o ensino da L2 para os surdos, é necessário, portanto, que nossa preocupação também seja a de despertar no aluno o interesse pela Língua Portuguesa, apresentando-lhe todos os motivos para isso. No entanto, ponderamos que essa não deva ser uma postura individual do professor, não alcançaria o resultado desejado. Necessitamos que essa negociação seja uma ação coletiva, em que todos os que participam desse contexto estejam sintonizados num único objetivo. O discurso precisa ser único. Não há como negar o papel da LIBRAS em suas vidas, é preciso reconhecê-lo para, em sequência, mostrar-lhes que para uma verdadeira inclusão não há também como negar o papel da Língua Portuguesa. 


\section{Referências Bibliográficas}

BAGNO, M. A norma oculta: língua \& poder na sociedade brasileira. São Paulo: Parábola Editorial, 2003.

BAGNO, M.; STUBS, M.; Gagné, G. Língua Materna: letramento, variação e ensino. São Paulo: Parábola, 2002.

BRASIL (2002) Lei $n^{\circ} 10.436$, de 24 de abril de 2002. Dispõe sobre a Língua Brasileira de Sinais - Libras e dá outras providências. Diário Oficial [da República Federativa do Brasil], Brasília, DF, n.79, p.23, 25 abr. Seção 1. 2002

BRASIL (2005) Decreto N 5.626 de 22 de dezembro de 2005. Brasília: Presidência da República, Casa Civil.

CAVALCANTI, M. C. "Estudos sobre Educação Bilíngue e Escolarização em Contextos de Minorias Linguísticas no Brasil”. DELTA, n. 15, 1999, p. 385-418.

CHOMSKY, N. "Of minds and language". In: Biolinguistics. V.1, n.1, 2007.

CHOMSKY, N. Linguagem e mente. Brasília: Editora da Unb, 1998.

CHOMSKY, N. Novos horizontes no estudo da linguagem e da mente. São Paulo: Ed. Unesp, 2005.

CHOMSKY, N. The Minimalist Program. Cambridg, MA: MIT Press, 1995.

FELIPE, T. A. “A estrutura frasal na LSCB”. In: Anais do IV Encontro Nacional da Anpoll, Recife, 1989.

FERREIRA BRITO, L. Por uma gramática de língua de sinais. Rio de Janeiro: Tempo Brasileiro, UFRJ, 1995.

KENEDY, E. \& ABRAÇADO, J. Aquisição da linguagem: palavras iniciais. Revista Gragoatá, Rio de Janeiro, v. 30, p. 11-36, 1.sem. 2011.

KRASHEN, S. D. "The monitor model for second-language acquisition". In: GINGRAS, R. C. (Ed.) Second-language acquisition \& foreign language teaching. Washington: Center for Applied Linguistics, 1978. p.1-26.

KRASHEN, S. D. Second Language Acquisition and Second Language Learning. Prentice-Hall International, 1988.

LENNEBERG, E. Biological foundations of Language. New York: Wiley, 1967.

LESSA-DE-OLIVEIRA, A. S. C. "Libras escrita: o desafio de representar uma língua tridimensional por um sistema de escrita linear". ReVEL, v. 10, n. 19, 2012. [www.revel.inf.br]. 
MEHLER, J. DUPOUX, E. Nascer Humano. Lisboa: Instituto Piaget. 1994.

MENEZES, V.; SILVA, M. M.; GOMES, I. F. "Sessenta anos de Linguística Aplicada: de onde viemos e para onde vamos". In: PEREIRA, R.C.; ROCA, P. Linguistica aplicada: um caminho com diferentes acessos. São Paulo: Contexto, 2009.

QUADROS, R. M. de. "A estrutura frasal da Língua Brasileira de Sinais". In: CONGRESSO NACIONAL DA ABRALIN, 1999, Florianópolis. Anais do II Congresso Nacional da ABRALIN. Florianópolis: UFSC, 2000.

QUADROS, R. M. de. "Aspectos da Sintaxe e da aquisição da língua de sinais brasileira". Letras de hoje, v.10, Porto Alegre, 1997.

QUADROS, R. M. de. "O contexto escolar do aluno surdo e o papel das línguas". Revista Espaço, INES, 1998.

QUADROS, R. M. de. "Políticas linguísticas e educação de surdos". In: V Congresso Internacional e XI Seminário Nacional do INES, 2006, Rio de Janeiro. Anais do Congresso: Surdez, família, linguagem e educação. Rio de Janeiro: INES, 2007. v.1. p.94-102.

QUADROS, R. M. de. Educação de surdos: a aquisição da linguagem. Porto Alegre: Artmed, 1997.

QUADROS, R. M. de. Phrase structure of brasilian sign language. Tese (Doutorado), Porto Alegre: Pontifícia Universidade Católica do Rio Grade do Sul, 1999.

QUADROS, R. M. de; KARNOPP, L. B. Língua de sinais brasileira: estudos linguísticos. Porto Alegre: Artmed, 2004.

REVUZ, Christine. "A língua estrangeira entre o desejo de um outro lugar e o risco do exílio". In: SIGNORINI, I. (org.). Língua(gem) e identidade: elementos para uma discussão no campo aplicado. FAEP/Unicamp: Mercado de Letras, 1998, p. 213-230.

SILVA, I. R. ; KUMADA, K. M. O. ; HILDEBRAND, H. R. ; NOGUEIRA, A. S. “[...] Língua de sinais eu sei, mas o português é difícil : reflexões sobre políticas linguísticas e de identidade no contexto da surdez no fomento de práticas de letramento diferenciadas". In: XI Congresso Luso Afro Brasileiro de Ciências Sociais, 2011, Salvador/BA. Anais Eletrônicos. Salvador: UFBA, 2011.

STOKOE, W.C. Sign Language Structure. Silver Spring: Linstok Press, 1960.

VENTURI, M. A. "Aquisição de língua estrangeira numa perspectiva de estudos aplicados". In: DEL RÉ, A. (org). Aquisição da linguagem: uma abordagem psicolinguística. São Paulo: Contexto, 2006. 